Case Study

\title{
Optimalisasi Pendokumentasian Case Manager Rumah Sakit Tipe A Di Jakarta
}

\author{
Yandih Mardean', La Ode A.Rahman², Hanny Handiyani², Lilis Rayatin³ \\ Program Studi Magister Kepemimpinan dan Manajemen Keperawatan \\ Fakultas Ilmu Keperawatan Universitas Indonesia \\ Bidang Keperawatan RSUPN Dr. Cipto Mangunkusumo, Jakarta
}

\section{Article Info}

Article History:
Submit: February 12, 2021
Accepted: May 28, 2021
Publish: May 29, 2021
Key words:
Case Manager; Fungsi Case
Manager;
Pendokumentasian Case
Manager; Pilot Project

\begin{abstract}
Case management di Indonesia dikenal dengan Manajemen Pelayanan Pasien (MnPP) dan case manager disebut dengan Manajer Pelayanan Pasien (MPP). Fungsi case manager yaitu melakukan asesmen, perencanaan hingga evaluasi, koordinasi, advokasi, edukasi, serta kendali mutu dan biaya. Case manager dalam menjalankan peran dan fungsinya banyak mendapat tantangan baik dari pasien/keluarga, Dokter Penanggung Jawab Pasien (DPJP), Perawat Penanggung Jawab Pasien (PPJA), Profesional Pemberi Asuhan (PPA) lainnya, kepala ruangan, penunjang medis, penjamin dan RS/Yankes lain dalam sistem rujukan. Metode yang digunakan berupa case study dimulai dari identifikasi, analisis dan penetapan prioritas masalah, penyusunan plan of action, implementasi, sampai evaluasi. Sampel kegiatan ini adalah semua case manager atau total sampling berjumlah 23 orang. Identifikasi masalah didapatkan 5 (lima) masalah fungsi manajer. Prioritas pertama adalah belum optimalnya fungsi pengarahan dalam pedokumentasian case manager. Selanjutnya disusun analisis masalah menggunakan fishbone, Plan of Action (POA), implementasi dan evaluasi bersama tim case manager dan Bidang Pelayanan Keperawatan RSUPN DR. CIPTO MANGUNKUSUMO dengan luaran draft SPO (Standard Procedure Operational) Pendokumentasian Case Manager.
\end{abstract}

\section{PENDAHULUAN}

Case management di Indonesia dikenal dengan Manajemen Pelayanan Pasien (MnPP) dan case manager disebut dengan Manajer Pelayanan Pasien (MPP). Case manager dalam menjalankan peran dan fungsinya banyak mendapat tantangan baik dari pasien/keluarga, Dokter Penanggung Jawab Pasien (DPJP), Perawat Penanggung Jawab Pasien (PPJA), Profesional Pemberi Asuhan (PPA) lainnya, kepala ruangan, penunjang medis, penjamin dan RS/Yankes lain dalam sistem rujukan. Pelayanan kesehatan pasien melibatkan banyak profesi dan support system, perlunya koordinasi yang baik agar pelayanan yang diberikan sesuai, efektif dan efisien (Widyanti, 2016). Case management merupakan bentuk koordinasi dan integrasi antar Profesional Pemberi Asuhan (PPA) kepada pasien yang dilakukan oleh seorang case manager (Sutoto \& Nico, 2017).

Corresponding author:

Yandih Mardean ryandhi1428@gmail.com Jurnal Kepemimpinan dan Manajemen Keperawatan, Vol 4 No 1, Mei 2021 DOI: http://dx.doi.org/10.32584/jkmk.v4i1.865 
Kemampuan manajerial seorang case manager sangat diperlukan untuk melakukan peran dan fungsinya. Fungsi manajer dalam perencanaan, pengorganisasian, ketenagaan, pengarahan, dan pengendalian (Marquis, 2015) dan peran besar seorang pemimpin pun sangat diperlukan meliputi: peran interpersonal terdiri dari figurhead, leader role, liaison role; peran informasional terdiri dari monitor role, disseminator role, spokes person; dan peran pengambil keputusan terdiri dari enterpreuner, disturbance handler, resources allocator, negosiator (Robbins, 2017). Hal ini sejalan dengan case management yang merupakan proses mengkolaborasikan pengkajian, perencanaan, bantuan yang diperlukan, koordinasi asuhan, evaluasi dan advokasi untuk pelayanan pemenuhan kebutuhan pasien dan keluarga secara komprehensif (Tahan, Kurland, \& Baker, 2020). Case management meliputi: skrining kasus, asesmen, perencanaan perawatan, koordinasi perawatan, evaluasi dan tindaklanjut kasus (Harrison Dening, Knight, \& Love, 2018).

Tujuan penerapan case management adalah memberikan pelayanan pasien/keluarga yang komprehensif, aman, terintegrasi, terkoordinasi dan bermutu dengan pembiayaan yang efektif. Tujuan umumnya untuk memperoleh dan mengembangkan asuhan pasien dan keluarga yang komprehensif, efektif dan pembiayaan yang efisien dalam mengkoordinasikan pelayanan untuk hidup pasien yang lebih berkualitas (Thoma \& Waite, 2018). Pelayanan pasien dikoordinasikan dengan menggunakan komunikasi efektif dan sumber daya yang ada sehingga memberikan hasil pelayanan yang bermutu dengan biaya efektif (Tahan \& Treiger, 2016).

Fungsi case manager yaitu melakukan assessment, perencanaan hingga evaluasi, koordinasi, advokasi, edukasi, serta kendali mutu dan biaya. Kompetensi case manager yang kurang akan mempengaruhi hasil pelayanan berupa penundaan transfer, penundaan pulang, kendali biaya dan mutu, memanjangnya length of stay (LOS), readmisi pasien dengan kondisi perburukan (Avia, Handiyani, \& Nurdiana, 2019)

RSUPN DR. CIPTO MANGUNKUSUMO merupakan RS Tipe A di Jakarta sebagai top referral hospital memberikan pelayanan spesialis dan subspesialis dengan kasus pasien yang komplek (Kemenkes, 2020). RSUPN DR. CIPTO MANGUNKUSUMO hendaknya juga memiliki case manager yang kompeten dan handal agar manajemen pelayanan pasien dan pelayanan keperawatan yang diberikan dapat melampaui harapan pelanggan. Rumah sakit mampu memberikan pelayanan kedokteran spesialis dan subspesialis secara luas (Kemenkes, 2020). Berdasarkan data dari Bidang Pelayanan Keperawatan (Bidyankep) RSUPN DR. CIPTO MANGUNKUSUMO didapatkan jumlah case manager sebanyak 23 (dua puluh tiga) orang dengan data sebaran sebagai berikut : Instalasi Rawat Jalan Terpadu (IPRJT) berjumlah 4 orang, Instalasi Pelayanan Jantung Terpadu (IPJT) berjumlah 4 orang, Instalasi Pelayanan Terpadu (Mangunkusumo) Kencana berjumlah 8 orang, Instalasi Pelayanan Terpadu (Mangunkusumo) Kirana berjumlah 3 orang, Instalasi Pelayanan Terpadu (Mangunkusumo) Kiara berjumlah 1 orang, Unit Transplantasi dan Paliatif dari Bidyankep berjumlah 3 orang.

\section{METODE}

Metode yang digunakan berupa pilot project serta analisis hasil dan gap implementasi dengan pembahasan berdasarkan literature review. Kegiatan yang dilakukan dalam pilot project ini dimulai dari identifikasi, analisis dan penetapan prioritas masalah, penyusunan plan of action, implementasi, serta evaluasi. Unit kerja yang di ambil sebagai pilot project meliputi IPRJT (Instalasi Rawat Jalan Terpadu), IPJT (Instalasi Pelayanan 
Jantung Terpadu), IPT (Instalasi Pelayanan Terpadu) Kencana, IPT (Instalasi Pelayanan Terpadu) Kirana, IPT (Instalasi Pelayanan Terpadu) Kiara. Dasar pemilihan unit kerja di RSUPN DR. CIPTO MANGUNKUSUMO adalah unit kerja yang memiliki case manager dalam pelayanan pasien.

Dalam masa pandemik ini data mengenai fungsi case manager dikumpulkan dengan menggunakan metoda survei melalui kuesioner fungsi case manager yang diambil dari panduan praktik case manager yang dikeluarkan oleh Komite Akreditasi Rumah Sakit (KARS), wawancara, observasi lapangan, diskusi kelompok melalui whatsapp grup dan data sekunder yang didapat dari Bidang Pelayanan Keperawatan. Kuesioner diberikan kepada case manager untuk mendapatkan gambaran tentang profil dan pelaksanaan fungsi case manager di unit kerjanya. Kuesioner juga diberikan kepada semua case manager untuk mendapatkan persepsi tentang kemampuan menjalankan fungsinya. Metode observasi lapangan dilakukan untuk mengidentifikasi ketersediaan dan keterkinian dokumen dan pelaksanaan fungsi case manager di tingkat koorporasi dan ruang kerjanya. Data tambahan dari Bidang Pelayanan Keperawatan di dapat dari wawancara dan konsultasi langsung dengan menjaga protokol Kesehatan dan media daring dengan Sub Koordinator Pengembangan Profesi dan Integrasi Pelayanan Keperawatan (SKPPIPK) Bidang Pelayanan Keperawatan (Bidyankep) RSUPN DR. CIPTO MANGUNKUSUMO.

Populasi dalam penelitian ini adalah semua case manager yang berjumlah 23 (dua puluh tiga) di RSUPN Dr. Cipto Mangunkusumo Jakarta. Metode pengambilan sampel adalah dengan total sampling. Sampel diambil berjumlah 21 (dua puluh satu) orang. Case manager yang tidak ikut berpartisipasi dalam pengambilan data dengan alasan 1 (satu) orang adalah mahasiswa residensi sebagai praktikan dan 1 (satu) orang lagi tidak terinformasi karena hambatan komunikasi sistem online.

\section{HASIL}

Hasil wawancara dengan SKPPIPK Bidang Pelayanan Keperawatan di dapatkan data sentinel yang salah satu akar permasalahnya tidak ada dokumentasi case manager terkait dengan skrining awal yang harus di lakukan oleh seorang case manager.

Dari diskusi kelompok pada grup case manager didapatkan pernyataan bahwa tidak semua case manager mengikuti pelatihan terlebih dahulu sebelum menduduki jabatan, penerapan case manager masih bervariasi di unit kerja. Hasil wawancara teridentifikasi penerapan case management oleh case manager $\mathrm{di}$ RSUPN DR. CIPTO MANGUNKUSUMO masih bervariasi yaitu : temuan sentinel belum ada catatan skrining awal yang dilakukan case manager, pasien terkesan tidak terdeteksi lebih dini kondisi perburukannya (skrining/asesmen dilakukan, namun tidak ada dokumentasi di formulir), tim transplan: "pasien datang tanpa rekam medik, bagaimana menulisnya, tim stoma kencana: sudah dilakukan ke HIS dan google form", Tim Paliatif: "kadang saat jalan dengan Peserta Pendidikan Dokter Spesialis (PPDS), bisa PPDS yang menulis di Catatan Perkembangan Pasien Terintegrasi (CPPT). Bila datang sendiri, menulis di CPPT. Perlu di tentukan apa yang harus diisi, dan kapan juga perlu diperjelas batasan tugas-tugas case manager, seperti penjaminan pembiayaan?", Tim Kirana: edukasi sudah ada dan dilakukan, masuk ke rekam medik. "Apakah bila ada form lagi apakah tidak makan waktu?". Tim IPJT: "Case Management itu dari awal dirawat, dan sampai mau pulang, bagaimana dengan yang menghubungi di luar hari dan jam kerja", "mungkinkah dibuat menggunakan google form?". Hasil observasi lapangan didapatkan data sudah adanya buku 
panduan pelayanan Hospital Case Management RSUPN DR. CIPTO MANGUNKUSUMO tahun 2015 dan SPO pelaksanaan case management di masing masing unit kerja.

Hasil survei melalui kuesioner tentang persepsi case manager dalam fungsi manajemen, didapatkan masih perlunya dilakukan perbaikan pada semua fungsi manager yaitu: perencanaan, pengorganisasian, ketenagaan, pengarahan, dan pengendalian. Adapun data pendukungnya sebagai berikut = pada fungsi perencanaan di dapatkan data : 57,1 $\%$ belum menerapkan alur pasien dengan baik, 47,6 \% tidak melakukan asesmen pasien, 66,6 \% belum merencanakan program discharge planning; pada fungsi pengorganisasian di dapatkan data : 38,1\% belum melakukan konsultasi dan koordinasi dengan PPA Lain ; pada fungsi ketenagaan : $58 \%$ belum berpengalaman sebagai kepala ruangan, $52 \%$ case manager relative baru (1-2) tahun, Tingkat Pendidikan bervariasi, D3 = $33 \%$, terdapat PK 2 sebagai case manager, sebanyak $74 \%$ case manager belum mengikuti pelatihan (sertifikasi ) ; pada fungsi pengarahan di dapatkan data : 38,1\% belum mendorong pelayanan yang KMKB, 47,6 \% belum membantu proses transisi pasien, 71,4\% tidak mendokumentasikan kegiatan di Form A dan B ; pada fungsi pengendalian di dapatkan data : 52,2 \% tidak memantau Bed Occupation Rate (Damani et al.), 76,6 $\%$ tidak melakukan discharge Planning, $61,9 \%$ tidak memantau pasien home care/ control pasca rawat, 57,2 \% tidak memantau waiting list pasien ranap, 76,2 tidak memantau waiting list pasien operasi.

Dari data yang ditemukan kemudian dirumuskan permasalahan yang muncul adalah = pada fungsi perencanaan : belum optimalnya fungsi perencanaan dalam memberikan pengelolaan asuhan pasien ; pada fungsi pengorganisasian : belum optimalnya fungsi pengorganisasi dalam koordinasi dengan PPA lainnya; pada fungsi ketenagaan : belum optimalnya fungsi ketenagaan dalam memenuhi kompetensi case manager; pada fungsi pengarahan : belum optimalnya fungsi pengarahan dalam penyeragaman kegiatan dan dokumentasi case manager; pada fungsi pengendalian : belum optimalnya fungsi pengendalian dalam sistem pelaporan dan evaluasi pelayanan.

Selanjutnya permasalahan yang muncul dilakukan prioritas dengan urutan prioritas masalah sebagai berikut :(1).Belum optimalnya fungsi pengarahan dalam pendokumentasian case manager ;(2).Belum optimalnya fungsi perencanaan dalam memberikan pengelolaan asuhan pasien;(3).Belum optimalnya fungsi pengorganisasi dalam koordinasi dengan PPA lainnya;(4).Belum optimalnya fungsi ketenagaan dalam memenuhi kompetensi case manager; (5).Belum optimalnya fungsi pengendalian dalam sistem pelaporan dan evaluasi pelayanan. Selanjutnya masalah prioritas pertama hasil asesmen diatas dianalisis menggunakan diagram fishbone/ishikawa. 


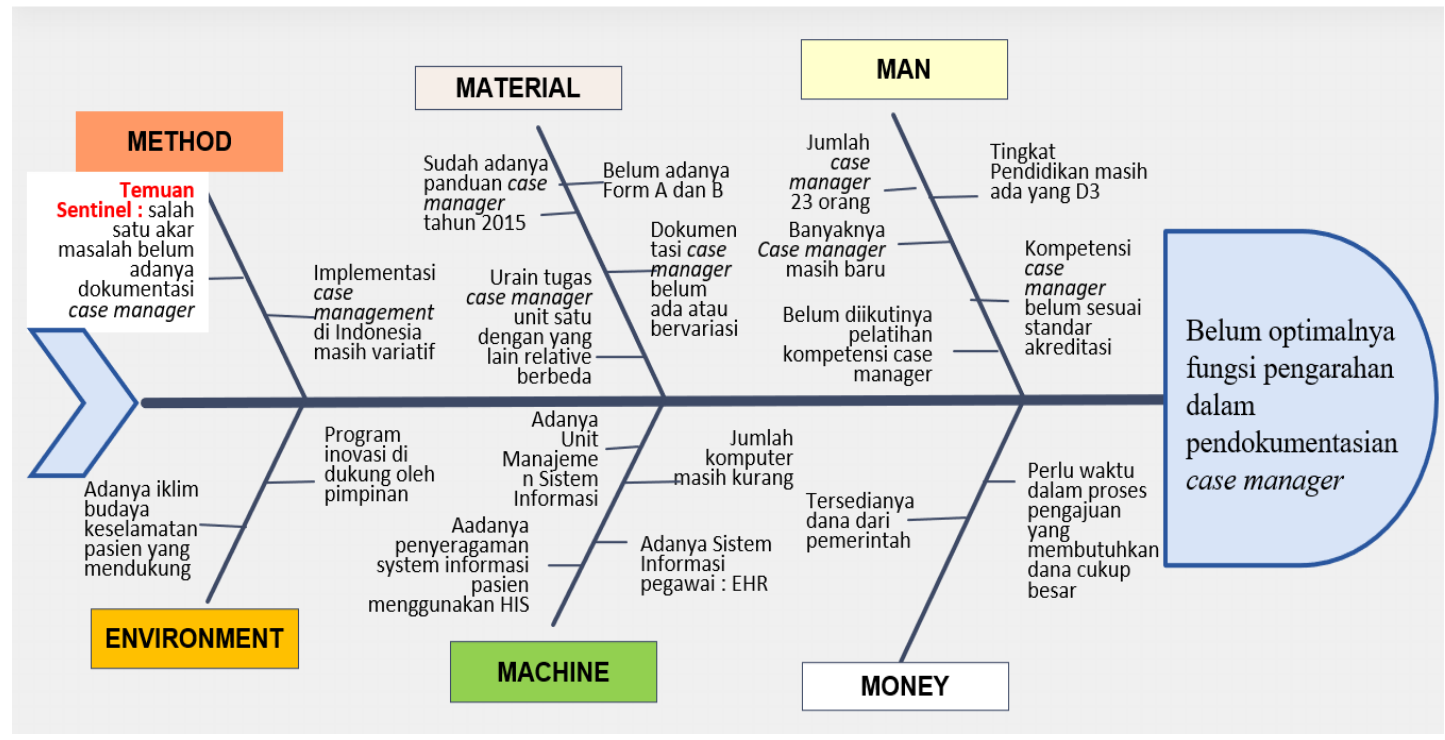

Gambar 1

Diagram fishbone belum optimalnya fungsi pengarahan dalam pendokumentasian case manager

Berdasarkan hasil analisis masalah prioritas pertama kemudian dilanjutkan dengan penyusunan POA. POA yang disusun dan disepakati adalah segera disusun Standar Prosedur Operasional (SPO) pendokumentasian case manager. Adapun proses penyusunannya terdiri dari enam Langkah, yaitu : Gambar Tabel 1 di bawah ini :

Tabel 1

Plan of Action (POA) Belum optimalnya fungsi pengarahan dalam pendokumentasian case manager

\begin{tabular}{|c|c|c|c|c|c|c|}
\hline Kegiatan & Tujuan & Sasaran & Media & Metode & Waktu & PIC \\
\hline $\begin{array}{l}\text { Konsultasi } \\
\text { rencana proyek } \\
\text { optimalisasi } \\
\text { fungsi case } \\
\text { manager dalam } \\
\text { pelayananan } \\
\text { pasien rawat } \\
\text { inap dan operasi }\end{array}$ & $\begin{array}{l}\text { Mendiskusikan } \\
\text { bersama } \\
\text { Bidyankep RSUPN } \\
\text { DR. CIPTO } \\
\text { MANGUNKUSUMO } \\
\text { sebagai gambaran } \\
\text { terkait rencana } \\
\text { inovasi }\end{array}$ & $\begin{array}{l}\text { Bidyankep } \\
\text { RSUPN DR. } \\
\text { CIPTO } \\
\text { MANGUNKUS } \\
\text { UMO }\end{array}$ & $\begin{array}{l}\text { Zoom } \\
\text { meeting }\end{array}$ & Diskusi & $\begin{array}{l}27 \\
\text { Oktober } \\
2020\end{array}$ & $\begin{array}{l}\text { Sub Koordinator } \\
\text { Pengembangan } \\
\text { Profesi dan } \\
\text { Integrasi } \\
\text { Pelayanan } \\
\text { Keperawatan } \\
\text { (SKPPIPK) } \\
\text { Bidyankep RSUPN } \\
\text { DR. CIPTO } \\
\text { MANGUNKUSUMO }\end{array}$ \\
\hline $\begin{array}{l}\text { Diskusi } \\
\text { Pendokumentasi } \\
\text { an: Skrining } \\
\text { pasien, Form A } \\
\text { dan Form B } \\
\text { (atau modifikasi } \\
\text { ) }\end{array}$ & $\begin{array}{l}\text { Memberi } \\
\text { gambaran } \\
\text { penerapan } \\
\text { dokumentasi case } \\
\text { manager }\end{array}$ & $\begin{array}{l}\text { Bidyankep, } \\
\text { Tim Case } \\
\text { Manager } \\
\text { RSUPN DR. } \\
\text { CIPTO } \\
\text { MANGUNKUS } \\
\text { UMO dan } \\
\text { Mahasiswa } \\
\text { Residensi } \\
\end{array}$ & $\begin{array}{l}\text { Zoom } \\
\text { meeting }\end{array}$ & Diskusi & $\begin{array}{l}27 \\
\text { Oktober } \\
2020\end{array}$ & $\begin{array}{l}\text { SKPPIPK } \\
\text { Bidyankep RSUPN } \\
\text { DR. CIPTO } \\
\text { MANGUNKUSUMO }\end{array}$ \\
\hline $\begin{array}{l}\text { Pembuatan SPO } \\
\text { pendokumentasi } \\
\text { an case manager: } \\
\text { Studi literatur, } \\
\text { diskusi dengan } \\
\text { tim case } \\
\text { manager dan } \\
\text { penyelesaian } \\
\text { tugas }\end{array}$ & $\begin{array}{l}\text { Menghasilkan } \\
\text { panduan } \\
\text { penerapan case } \\
\text { management } \\
\text { sesuai standar } \\
\text { akreditasi dan } \\
\text { referensi }\end{array}$ & $\begin{array}{l}\text { Mahasiswa } \\
\text { Residensi dan } \\
\text { Tim Case } \\
\text { Manager } \\
\text { RSUPN DR. } \\
\text { CIPTO } \\
\text { MANGUNKUS } \\
\text { UMO }\end{array}$ & Mandiri & $\begin{array}{l}\text { Diskusi, } \\
\text { literature } \\
\text { review }\end{array}$ & $\begin{array}{l}27 \\
\text { Oktober - } \\
3 \\
\text { November } \\
2020\end{array}$ & $\begin{array}{l}\text { SKPPIP Bidyankep } \\
\text { RSUPN DR. CIPTO } \\
\text { MANGUNKUSUMO }\end{array}$ \\
\hline
\end{tabular}




\begin{tabular}{|c|c|c|c|c|c|c|}
\hline Kegiatan & Tujuan & Sasaran & Media & Metode & Waktu & PIC \\
\hline $\begin{array}{l}\text { Pleno finalisasi } \\
\text { SPO } \\
\text { Pendokumentasi } \\
\text { an case manager }\end{array}$ & $\begin{array}{l}\text { Menghasilkan SPO } \\
\text { Pendokumentasia } \\
\text { n case manager } \\
\text { sesuai standar } \\
\text { akreditasi dan } \\
\text { referensi }\end{array}$ & $\begin{array}{l}\text { Bidyankep } \\
\text { Tim case } \\
\text { manager } \\
\text { Komkep, } \\
\text { Mahasiswa } \\
\text { Residensi }\end{array}$ & $\begin{array}{l}\text { Zoom } \\
\text { meeting }\end{array}$ & Diskusi, & $\begin{array}{l}4 \\
\text { November } \\
2020\end{array}$ & $\begin{array}{l}\text { SKPPIP K } \\
\text { Bidyankep RSUPN } \\
\text { DR. CIPTO } \\
\text { MANGUNKUSUMO }\end{array}$ \\
\hline $\begin{array}{l}\text { Pengajuan } \\
\text { Pengesahan } \\
\text { Draft SPO } \\
\text { Pendokumentasi } \\
\text { an case manager }\end{array}$ & $\begin{array}{l}\text { Legalitas SPO } \\
\text { Pendokumentasia } \\
\text { nyang di sahkan } \\
\text { oleh direktur }\end{array}$ & $\begin{array}{l}\text { Bidyankep } \\
\text { Tim case } \\
\text { manager }\end{array}$ & $\begin{array}{l}\text { Zoom } \\
\text { meeting }\end{array}$ & $\begin{array}{l}\text { Diskusi, } \\
\text { literature } \\
\text { review }\end{array}$ & $\begin{array}{l}5-30 \\
\text { November } \\
2020\end{array}$ & $\begin{array}{l}\text { SKPPIPK } \\
\text { Bidyankep RSUPN } \\
\text { DR. CIPTO } \\
\text { MANGUNKUSUMO }\end{array}$ \\
\hline $\begin{array}{l}\text { Sosialisasi SPO } \\
\text { Pendokumentasi } \\
\text { an case manager }\end{array}$ & $\begin{array}{l}\text { Menyamakan } \\
\text { pesepsi sesama } \\
\text { case manager dan } \\
\text { sosialisasi dengan } \\
\text { DPJP, PPA Lainnya, } \\
\text { SPO } \\
\text { Pendokumentasia } \\
\text { n case manager }\end{array}$ & $\begin{array}{l}\text { Bidyankep } \\
\text { Komkep } \\
\text { Tim case } \\
\text { manager } \\
\text { HN/ NO/ } \\
\text { Kepala } \\
\text { Ruangan }\end{array}$ & $\begin{array}{l}\text { Zoom } \\
\text { Meeting }\end{array}$ & Diskusi & $\begin{array}{l}30 \\
\text { November } \\
2020\end{array}$ & $\begin{array}{l}\text { SKPPIP K } \\
\text { Bidyankep RSUPN } \\
\text { DR. CIPTO } \\
\text { MANGUNKUSUMO }\end{array}$ \\
\hline
\end{tabular}

Implementasi dari POA yang telah disusun dan disepakati bersama di era pandemi ini dilakukan dengan memperhatikan protokol kesehatan dan memanfaatkan berbagai media daring. Kegiatan (1): Konsultasi rencana proyek optimalisasi fungsi case manager dalam pelayananan pasien rawat inap dan operasi. Kegiatan ini dilakukan dengan metode daring (zoomeeting) didapatkan data templete dan gambaran SPO yang akan dibuat dari SKPPIPK Bidang Pelayanan Keperawatan dan Kegiatan (2): Diskusi Pendokumentasian: Skrining pasien, Form A dan Form B (atau modifikasi) dilakukan bersamaan dengan kegiatan 1 didapatkan kondisi dan perlunya pendokumentasian di modifikasi dengan memanfaatkan system IT yang sudah ada. Kegiatan (3): Pembuatan SPO pendokumentasian case manager : Studi literatur, diskusi dengan tim case manager dan penyelesaian tugas. Kegiatan (4): Pleno finalisasi SPO Pendokumentasian case manager, kegiatan ini sedianya direncanakan tanggal 4 November 2020 karena kendala kesibukan dan padatnya acara di Bidang Pelayanan Keperawatan menyesuaikan menjadi tanggal 6 November 2020 adapun hasilnya sebagai berikut: perlunya revisi SPO berdasarkan hasil diskusi Bidyankep dan tim case manager. Kegiatan (5) : Pengajuan Pengesahan Draft
SPO Pendokumentasian case manager; Kegiatan (6): Sosialisasi SPO Pendokumentasian case manager rencana kegiatan, kegiatan ini akan dilakukan 30 November 2020 atau apabila SPO sudah disahkan oleh Direktur Utama RSUPN DR. CIPTO MANGUNKUSUMO, Kegiatan sosialiasi akan dilakukan oleh SKPPIPK Bidyankep RSUPN DR. CIPTO MANGUNKUSUMO. Hasil akhir program residensi adalah tersusunnya draft SPO Pendokumentasian case manager telah selesai dilaporkan ke pimpinan rumah sakit dan disosialisasikan kepada para case manager dan unit terkait di RSUPN Dr. Cipto Mangunkusumo Jakarta yang akan dikoordinir oleh Bidang Pelayanan Keperawatan.

\section{PEMBAHASAN}

Hasil wawancara dengan Bidang Pelayanan Keperawatan khususnya SKPPIPK terlihat memiliki persepsi yang sangat positif terhadap pengembangan case management di RSUPN DR. CIPTO MANGUNKUSUMO sebagai manajer yang dapat membantu pelayanan pasien yang terkoordinir yang mengedepankan keselamatan pasien dan Kendali Mutu Kendali Biaya (KMKB). Hal ini sejalan dengan beberapa penelitian, diantaranya: semua intervensi case 
manager sejalan dengan Case Management Society of America (CMSA); dalam melakukan penilaian dan perencanaan, pendidikan, layanan transisi, rujukan ke layanan dasar atau sosial atau kesehatan lainnya, dan kontak tatap muka atau telepon untuk tindak lanjut rutin (Joo \& Huber, 2019); Fungsi navigator pasien dan manajer kasus diatur ke dalam sembilan kategori yang muncul: (1) advokasi; (2) koordinasi perawatan; (3) pemantauan kasus dan penilaian kebutuhan pasien; (4) keterlibatan masyarakat; (5) pendidikan; (6) kegiatan administrasi dan penelitian; (7) dukungan psikososial; (8) navigasi layanan; dan (9) pengurangan hambatan. Latar belakang dan bidang pengetahuan masing-masing peran dibandingkan dan dikontraskan, dan tiga kategori yang terkait dengan konteks praktik dari masing-masing peran diidentifikasi: (1) pengaturan khas dan lintasan perawatan; (2) target populasi pasien; dan (3) cara penyampaian layanan. (Kelly, Doucet, \& Luke, 2019).

Dari diskusi kelompok pada grup case manager didapatkan pernyataan bahwa tidak semua case manager mengikuti pelatihan terlebih dahulu sebelum menduduki jabatan. Ini merupakan kesenjangan dimana Implementasi case management oleh seorang case manager hendaknya sejalan dengan pengembangan pendidikan berkelanjutan. Pendidikan berkelanjutan bertujuan untuk mempertahankan kompetensi, meningkatkan profesionalisme, keahlian dan keterampilan perawat (Katsikitis et al., 2013).

Seorang manajer sangat perlu diberikan pembekalan pengetahuan dan keterampilan manajerial agar mampu menampilkan kepemimpinannya (Marquis, 2015). Keperawatan sebagai profesi dituntut menjamin kualitas pelayanannya, serta menjamin bahwa setiap anggotanya mempunyai kompetensi yang senantiasa dipelihara dan ditingkatkan. Peningkatan kompetensi merupakan kewajiban setiap perawat untuk melakukannya. PPNI sebagai organisasi profesi memfasilitasi anggotanya melalui kegiatan.(PPNI, 2017).

Dari diskusi kelompok case manager juga di dapatkan data bahwa penerapan case manager masih bervariasi di unit kerja dan adanya temuan sentinel dikarenakan belum ada catatan skrining awal yang dilakukan case manager, pasien terkesan tidak terdeteksi lebih dini kondisi perburukannya (skrining/asesmen dilakukan, namun tidak ada dokumentasi di formulir). Hal ini sejalan dengan (Sutoto \& Nico, 2017) dalam buku panduan Panduan Praktik Manajer Pelayanan Pasien - MPP di Rumah Sakit (Case Manager) yang dikeluarkan oleh Komite Akreditasi Rumah Sakit (KARS) bahwa implementasi pengelolaan dan pelayanan pasien masih variasi, untuk saat ini diperlukan pengaturan dalam panduan atau SPO di Rumah Sakit masing -masing.

Lima tema diidentifikasi sebagai hambatan implementasi manajemen kasus: ruang lingkup praktik yang tidak jelas, aktivitas manajemen kasus yang beragam dan kompleks, pelatihan yang tidak memadai, kolaborasi yang kurang baik dengan penyedia layanan kesehatan lain, dan tantangan hubungan klien. Studi tinjauan ini menyarankan bahwa protokol praktis berbasis bukti dan program sertifikasi standar dapat membantu mengatasi hambatan manajer kasus dan meningkatkan praktik manajemen kasus. Pembuat kebijakan, asosiasi manajemen kasus, dan peneliti manajemen perawatan kesehatan harus mengembangkan dukungan pendidikan dan praktik untuk manajer kasus (Thoma \& Waite, 2018).

Dari data survei masih di dapatkan kesenjangan di semua fungsi manajer. Fungsi manajer yang dilakukan survey adalah : perencanaan, pengorganisasian, ketenagaan, pengarahan, dan pengendalian (Marquis, 2015). Perencanaan merupakan Suatu upaya memutuskan apa yang akan dilakukan, siapa, bagaimana, kapan dan dimana hal itu akan dilakukan,dalam mengidentifikasi tujuan jangka panjang dan 
pendek dapat dicapai, spesifik, berorientasi pada saat ini dan masa akan datang (Marquis, 2015). Suatu proses yang terdiri atas mendefinisikan tujuan, menyusun strategi, dan mengembangkan, rencana untuk mengoordinasi aktivitas (Robbins, 2017). Berdasarkan data yang di dapatkan dalam perencanaan perlunya membuat, memahami dan melaksanakan alur pasien dengan baik, melaksanakan asesmen, merencanakan program discharge planning (Sutoto \& Nico, 2017); Fungsi pengorganisasian adalah proses menentukan tugas - tugas apa yang akan dikerjakan, siapa yang mengerjakannya, bagaimana tugas-tugas ini dikelompokan, siapa yang melapor pada siapa dan di mana keputusan harus dibuat (Robbins, 2017).

Fungsi pengorganisasian ditemukan data bahwa case manager belum melakukan konsultasi dan koordinasi dengan PPA Lain. Hal ini tidak sejalan dengan case manager adalah seseorang yang membantu pasien sebagai penghubung antara pasien, keluarga dan para dokter. Seorang case manager harus mengerti kondisi pasien dan pengobatannya agar dapat membantu pasien memahaminya pula (Sutoto \& Nico, 2017). Peran Case Manager menurut (CMSA, 2017), antara lain: (1). Melakukan pengkajian komprehensif pada kesehatan pasien dan kebutuhan psikologis pasien, dan mengembangkan perencanaan case management dengan berkolaborasi dengan pasien dan keluarga; (2). Membuat perencanaan dengan pasien, keluarga, DPJP, atau pemberi pelayanan yang lain, penanggung biaya, untuk meningkatkan respon perawatan, kualitas, cost effective; (3). Memfasilitasi proses komunikasi dan koordinasi antara tenaga kesehatan, termasuk pasien dalam proses pengambilan keputusan;(4). Memberikan edukasi ke pasien, keluarga, dan tim pemberi pelayanan kesehatan terkait pilihan terapi, manfaat asuransi, case management, sehingga keputusan dapat diambil pada saat itu; (5). Memberdayakan pasien untuk terlibat dalam pengambilan keputusan dengan mengeksplorasi pilihan perawatan yang akan dilakukan, rencana alternative terkait kondisi kesehatan pasien ; Fungsi ketenagaan adalah suatu fungsi manajamen dalam mengembangkan formula ketenagaan, untuk melakukan tugas keperawatan agar dapat memberikan pelayanan dan malakukan tugas memberi asuhan keperawatan (Swansburg, 1999).

Fungsi ketenagaan adalah rekrutmen, latihan dan pengembangan serta penempatan dan pemberian orientasi pada karyawan dalam lingkungan kerja yang menguntungkan dan produktif (Robbins, 2017). Data yang ditemukan fungsi ketenagaan : adanya case manager belum berpengalaman sebagai kepala ruangan, case manager relatif baru (1-2) tahun, Tingkat Pendidikan masih ada yang D3, terdapat PK 2 sebagai case manager, case manager belum mengikuti pelatihan (sertifikasi). Hal ini tidak sesuai dengan prasyarat dan kompetensi menjadi seorang case manager dimana seorang case manager perawat harus pendidikan minimal S1Ners, memiliki pengalaman sebagai Profesional Pemberi Asuhan (PPA) minimal 3 tahun, pengalaman sebagai kepala ruang rawat minimal 2 tahun, dan perlu pelatihan pendukung yaitu pelatihan peningkatan pengetahuan terkait dengan penyusunan dan penerapan SPO Pelayanan kedokteran yang terdiri dari Panduan praktik klinis, Clinical pathway, Alogaritme, protokol, standing order, Pelatihan Pelayanan Focus pada Pasien ( PFP) atau Patient Centered Care (PCC), Pelatihan tentang perasuransian, jaminan kesehatan nasional dan INA-CBG's, Pelatihan Discharge Planning, Pelatihan manajemen resiko, Pelatihan etika-legal dan Pelatihan soft skill seperti aspek psiko-sosio-kultural, komunikasi interpersonal (Sutoto \& Nico, 2017); Fungsi pengarahan bagaimana membuat atau mendapatkan para karyawan melakukan apa yang diinginkan dan harus mereka lakukan. Tujuan dari pengarahan adalah menciptakan kerjasama yang efisien, mengembangkan kemampuan dan ketrampilan staf, menumbuhkan rasa memiliki dan menyukai pekerjaan, 
menciptakan suasana lingkungan kerja yang meningkatkan motivasi dan prestasi kerja dan membuat organisasi berkembang dengan dinamis (Robbins, 2017). Pada fungsi pengarahan di dapatkan data: mayoritas case manager belum mendorong pelayanan yang Kendali Mutu Kendali Biaya (KMKB), belum membantu proses transisi pasien, tidak kegiatan mendokumentasikan kegiatan di Form A dan B. Hal ini tidak sejalan dengan Fungsi case manager yaitu melakukan assesment hingga evaluasi perencanaan, koordinasi, advokasi, edukasi, serta kendali mutu dan biaya Kompetensi case manager yang kurang akan mempengaruhi hasil pelayanan berupa penundaan transfer, penundaan pulang, kendali biaya dan mutu, memanjangnya length of stay (LOS), readmisi pasien dengan kondisi perburukan meningkat Avia et al. (2019); Fungsi pengendalian merupakan penemuan dan penerapan cara dan alat untuk menjamin bahwa rencana telah dilaksanakan sesuai dengan yang telah ditetapkan (Robbins, 2017). Melakukan kendali mutu dengan proaktif, aktif secara politik mengkomunikasikan kendali mutu dan implikasinya kepada tenaga kesehatan lain dan konsumen, bertindak sebagai role model tanggung jawab dan tanggung gugat untuk tindakan keperawatan, memastikan pasien mendapat pelayanan bermutu yang sesuai asuhan, berpartisipasi aktif dalam kegiatan penelitian, menggunakan temuan kendali mutu sebagai ukuran kinerja, penentu sistem penghargaan, membimbing, memberikan konseling dan mendisiplinkan pegawai dengan tindakan yang tepat, mengikuti regulasi pada saat ini seperti berkaitan dengan akreditasi, serta regulasi kendali mutu, berpartisipasi aktif dalam sosialisasi pengukuran standar nasional (Marquis, 2015). pada fungsi pengendalian di dapatkan data : adanya case manager tidak memantau BOR, tidak melakukan discharge planning, tidak memantau pasien home care/ control pasca rawat, tidak memantau waiting list pasien ranap dan tidak memantau waiting list pasien operasi. Dalam hal ini sudah seharusnya seorang case manager dapat memenuhi hak pasien melalui komunikasi yang efektif. Case manager bekerja erat dengan pasien sehingga waktu perawatan terhadap pasien berlangsung lama sejak pasien datang ke rumah sakit sampai pulang ke rumah pasien. Case manager melalui perannya dalam mengumpulkan dan mengatur berbagai data yang berkaitan dengan pasien dan proses perawatan sesuai penyakitnya, kebutuhan, dan potensi yang ada pada pasien sehingga mempertemukan kebutuhan/harapan dan kepatuhan pasien (Aeni, 2014) Ketika diterapkan secara efektif, ini meningkatkan kualitas dan keamanan perawatan pasien dan mengurangi biaya yang tidak perlu sekaligus meningkatkan pengalaman pasien. Karena case management menghubungkan tiga elemen struktur, proses, dan hasil, case manager dapat menjalankan fungsi penting dalam membantu organisasi mereka dalam mengukur kualitas perawatan.(Cesta, 2017).

Dari Lima masalah yang data urutan prioritas masalah sebagai berikut: (1). Belum optimalnya fungsi pengarahan dalam pendokumentasian case manager; (2). Belum optimalnya fungsi perencanaan dalam memberikan pengelolaan asuhan pasien; (3). Belum optimalnya fungsi pengorganisasi dalam koordinasi dengan PPA lainnya; (4). Belum optimalnya fungsi ketenagaan dalam memenuhi kompetensi case manager; (5). Belum optimalnya fungsi pengendalian dalam sistem pelaporan dan evaluasi pelayanan. Proses penentuan prioritas sudah sesuai berdasarkan skoring dan penilaiannya dilakukan bersama-sama dengan tim case manager RSUPN DR. CIPTO MANGUNKUSUMO bersama dengan Bidang Pelayanan Keperawatan.

Skoring dinilai berdasarkan risiko terjadi, risiko parah, potensi untuk pelatihan, minat perawat, mungkin diatasi, sesuai progres, tempat, waktu, dana, fasilitas kesehatan, sumber daya dan sesuai dengan peran perawat dimana didapatkan data prioritas pertama yang akan diatasi dalam proyek 
residensi ini. Tahap selanjutnya masalah prioritas pertama dilakukan analisis dengan diagram fishbone/ishikawa ditemukan akar permasalahan yang akan dibuat perencanaan untuk mengatasinya dalam Planning of Action (POA). Hal ini sudah sesuai dengan teori dimana POA disusun bersama-sama dengan SKPPIPK Bidang Pelayanan Keperawatan dan tim case manager RSUPN DR. CIPTO MANGUNKUSUMO. Setelah POA tersusun selanjutnya dilakukan proses implementasi sudah sesuai dengan perencanaan yang disusun. Kegiatan 4 yaitu Pleno finalisasi SPO Pendokumentasian case manager, kegiatan ini sedianya direncanakan tanggal 4 November 2020 karena kendala kesibukan dan padatnya acara di Bidang Pelayanan Keperawatan menyesuaikan menjadi tanggal 6 November 2020. Hal ini akan berpotensi membuat mundur juga kegiatan 5 yaitu Pengajuan Pengesahan Draft SPO Pendokumentasian case manager dan kegiatan 6 yaitu sosialisasi SPO pendokumentasian case manager dikarenakan proses residensi sudah selesai. Kegiatan 5 dan 6 dilanjutkan oleh SKPPIPK Bidyankep RSUPN DR. CIPTO MANGUNKUSUMO.

\section{SIMPULAN}

$\begin{array}{lrr}\text { Implementasi } & \text { penyusunan } & \text { Standar } \\ \text { Prosedur } & \text { Operasional } & \text { (SPO) }\end{array}$ Pendokumentasian Case Manager RSUPN DR. CIPTO MANGUNKUSUMO dapat dilaksanakan sesuai dengan yang direncanakan. Keterlibatan tim serta dukungan dari Bidang Pelayanan Keperawatan khususnya SKPPIPK Bidang Pelayanan Keperawatan sangat diperlukan sehingga optimalisasi fungsi case manager dalam pendokumentasian dapat dilaksanakan dengan baik. Proyek residensi memiliki keterbatasan karena waktu implementasi yang sangat singkat sehingga evaluasi kurang optimal.

\section{UCAPAN TERIMAKASIH}

Penulis mengucapkan terimakasih kepada semua pihak yang telah membantu dalam penyelesaian studi ini.

\section{REFERENSI}

Aeni, W. N. (2014). Pengembangan Case Manager dalam Patient Centre Care. Jurnal Manajemen Keperawatan, Volume 2, No. 2, November 2014; 126-134.

Avia, I., Handiyani, H., \& Nurdiana, N. (2019). Analisis Kompetensi Case Manager Pada Rumah Sakit Di Jakarta: Studi Kasus. Jurnal Perawat Indonesia, 3(1), 16-27.

Cesta, T. (2017). Quality of Care and the Role of the Case Manager. ProQuest, Atlanta Vol. 25, Iss. 6.

CMSA. (2017). CMSA Core Curriculum for Case Management: Lippincott, Williams \& Wilkins.

Damani, Z., Conner-Spady, B., Nash, T., Tom Stelfox, H., Noseworthy, T. W., \& Marshall, D. A. (2017). What is the influence of single-entry models on access to elective surgical procedures? A systematic review. BMJ Open, 7(2), e012225. doi:10.1136/bmjopen-2016012225

Harrison Dening, K., Knight, C., \& Love, A.-M. (2018). Admiral Nursing: case management for families affected by dementia. International Journal of Integrated Care, 18(s2), 164. doi:10.5334/ijic.s2164

Joo, J. Y., \& Huber, D. L. (2019). Case Management Effectiveness on Health Care Utilization Outcomes: A Systematic Review of Reviews. In (Vol. 41, pp. 111-133). Los Angeles, CA: SAGE Publications.

Katsikitis, M., McAllister, M., Sharman, R., Raith, L., Faithfull-Byrne, A., \& Priaulx, R. (2013). Continuing professional development in nursing in Australia: Current awareness, practice and future directions. Contemporary Nurse, 45(1), 33-45. doi:10.5172/conu.2013.45.1.33

Kelly, K. J., Doucet, S., \& Luke, A. (2019). Exploring the roles, functions, and background of patient navigators and case managers: A scoping review. International Journal of Nursing Studies, 98, 27-47. doi:10.1016/j.ijnurstu.2019.05.016

Kemenkes. (2020). Peraturan Menteri Kesehatan Republik Indonesia Nomor 3 Tahun 2020 
Tentang Klasifikasi Dan Perizinan Rumah Sakit. JAKARTA

Mangunkusumo, R. D. C. (2020). Rencana Strategis Bisnis 2020 - 2024. Retrieved from JAKARTA:

Marquis. (2015). Leadership Roles an Management Functions in Nursing. Philadelphia:: Wolters Kluwer Health.Lippincott Williams \& Wilkins.

PPNI. (2017). Pedoman Pendidikan Keperawatan Berkelanjutan (PKB) Perawat Indonesia. In (Vol. JILID III). JAKARTA: DPP PPNI.

Robbins. (2017). Organizational behavior (Vol. 17). GLOBAL EDITION: Pearson Education Limited.

Sutoto, D., dr, M.Kes, \& Nico, A. L., dr, Sp.PD, K.Nefro, MM, MHKes. (2017). Panduan Praktik Manajer Pelayanan Pasien - MPP di Rumah Sakit (Case Manager). Jakarta: KARS.

Swansburg, R. C. S., R.J. (1999). Introductory management and leadership for nurses. Canada: Jones and Barlett Publishers.
Tahan, H. M., Kurland, M., \& Baker, M. (2020). Understanding the Increasing Role and Value of the Professional Case Manager: A National Study From the Commission for Case Manager Certification: Part 1. Professional Case Management, 25(3).

Tahan, H. M., \& Treiger, T. M. (2016). CMSA Core Curriculum for Case Management (3 ed.). Hagerstown: Wolters Kluwer Health.

Thoma, J. E., \& Waite, M. A. (2018). Experiences of nurse case managers within a central discharge planning role of collaboration between physicians, patients and other healthcare professionals: A sociocultural qualitative study. Journal of Clinical Nursing, 27(5-6), 1198-1208. doi:10.1111/jocn.14166

Widyanti. (2016). Budaya Organisasi yang Mendukung Keselamatan Pasien di Rumah Sakit. Jurnal Teknik Industri, Vol. 18, No. 2, Desember 2016, 95-102. 